\title{
Reduced expression of $\alpha$ catenin is associated with poor prognosis in colorectal carcinoma
}

\author{
K M Ropponen, M J Eskelinen, P K Lipponen, E M Alhava, V-M Kosma
}

\begin{abstract}
Aims-To investigate $\alpha$ catenin expression in surgically resected human colorectal cancers to evaluate its prognostic value during long term follow up.

Methods-Immunohistochemistry was used to compare the expression of $\alpha$ catenin with conventional prognostic factors in 187 colorectal cancer patients treated in Kuopio University Hospital and followed up for a mean of 14 years. The hypothesis that the intensity of expression of $\alpha$ catenin and its distribution in cancer cells is correlated with survival was tested with the log-rank test, hazard ratios, and their confidence intervals.

Results-Uniform membranous $\alpha$ catenin staining localised to the intercellular borders was observed in $46 \%$ of the tumours; $55 \%$ of all tumours had either heterogeneous or negative $\alpha$ catenin expression, and staining intensity was either negative or weak in $42 \%$ of the tumours. The cancer related and recurrence-free survival rates were lower among patients with a weak $\alpha$ catenin intensity in tumour epithelium $(p<0.001)$, a low fraction of positive tumour cells $(p<0.001)$, and an additional cytoplasmic accumulation of $\alpha$ catenin $(p<0.001)$. In multivariate analysis, the intensity of $\alpha$ catenin expression in tumour epithelium predicted cancer related survival independently; $\alpha$ catenin localisation in tumour epithelium was an independent prognostic factor of recurrence-free survival in the group as a whole and in the T1-3N0M0 tumour subgroup.

Conclusions-A low proportion of positive carcinoma cells, additional cytoplasmic accumulation of $\alpha$ catenin, and reduced expression intensity in tumour epithelium predict a poor survival rate. The results suggest that $\alpha$ catenin has prognostic significance in colorectal cancer.

(f Clin Pathol 1999;52:10-16)
\end{abstract}

Keywords: $\alpha$ catenin; colorectal cancer; prognosis

Dukes staging and the Jass grouping system ${ }^{1}$ are the most commonly used prognostic indicators in colorectal cancer, which is one of the most frequently diagnosed cancers in Western countries. ${ }^{2}$ However, there is variation in the prognosis within the same Dukes category. In Dukes B tumours in particular, more accurate prognostic determinants are needed, since the number of available treatments is constantly increasing. ${ }^{3}$ In addition, poorly differentiated carcinomas-which invade and metastasise most rapidly - are associated with a worse prognosis than moderately differentiated carcinomas. Identifying alterations within carcinoma cells that cause this variation in invasiveness could lead to identification of a subset of patients with potentially more aggressive tumours. Such patients could benefit from more effective adjuvant treatment. ${ }^{4}$

The invasion and metastasis of cancers are complex processes, and the initial step is escape of cancer cells from the primary tumour. This involves disruption of normal cell-cell adhesion. ${ }^{5}$ The linkage between transmembranous cadherins and actin filament in the cytoskeleton is necessary for the formation of strong cell-cell adhesion and is mediated by many different undercoat proteins at the junction. ${ }^{5}$ Catenins are a series of undercoat proteins that interact with the intracellular domain of E-cadherin. They are $\alpha$ catenin (102 $\mathrm{kDa}), \beta$ catenin $(88 \mathrm{kDa})$, and $\gamma$ catenin $(82$ $\mathrm{kDa})$. The $\alpha$ catenin gene is located at chromosome 5q21-22, and has been shown to be involved in the development of certain tumours. ${ }^{6}$ Deletion of the $\alpha$ catenin gene, mutation of the $\alpha$ catenin protein, and mutation of the intracellular domain of E-cadherin, which allows interaction between E-cadherin and $\alpha$ catenin, results in nonaggregating, non-adhesive cells. ${ }^{7}$ The reduction of $\alpha$ catenin expression has been correlated with tumour dedifferentation, infiltrative growth, and lymph node metastasis in oesophageal, renal, prostate, and breast carcinomas. $^{5-10}$ However, the prognostic role of $\alpha$ catenin in different human tumours has not yet been defined.

Because little information is available on the prognostic value of $\alpha$ catenin in colorectal cancer survival, we investigated its expression in surgically resected human colorectal cancers during long term follow up.

\section{Methods}

PATIENTS

We studied 187 patients treated for colorectal adenocarcinoma between 1976 and 1986, and subsequently followed up for a mean of 14.0 years. Patients were selected from an original cohort of 308 patients but the remaining 121 patients were excluded because the histological material available for $\alpha$ catenin staining was inadequate (the samples contained either too little tumour tissue or there was no tumour left in the section). The clinical staging of all the tumours was completed according to the Union Internationale Contre le Cancer
Accepted for publication 25 August 1998 
Table 1 Clinicopathological data on the patients

\begin{tabular}{|c|c|}
\hline Number of patients & 187 \\
\hline Mean age, years (SD) (range) & 65.6 (11.1) 33.0 to 88.0$)$ \\
\hline $\operatorname{Sex}(F / M)$ & $92 / 95$ \\
\hline Mean follow up, years (SD) & $14.0(3.7)$ \\
\hline \multicolumn{2}{|l|}{ Type of primary treatment } \\
\hline Operation & 187 \\
\hline Operation + chemotherapy & 22 \\
\hline Operation + radiotherapy & 17 \\
\hline \multicolumn{2}{|l|}{ Surgical treatment } \\
\hline Total colectomy & 6 \\
\hline Hemicolectomy & 55 \\
\hline Anterior resection of rectum & 54 \\
\hline Abdominoperineal resection & \\
\hline of rectum & 31 \\
\hline Local excision & 5 \\
\hline Resection of sigmoid & 24 \\
\hline Exploratory laparotomy & 12 \\
\hline $\mathrm{T}$ category: Tis, $1,2,3,4, \mathrm{X}$ & $2,12,31,124,15,3$ \\
\hline $\mathrm{N}$ category: $0,1,2,3, \mathrm{X}$ & $122,39,17,4,5$ \\
\hline$M$ category: 0,1 & 138,49 \\
\hline Histological grade: $1,2,3$ & $50,111,26$ \\
\hline TIL grade: $0,1,2,3$ & $11,114,50,12$ \\
\hline Dukes: $0, A, B, C, D$ & $2,31,73,32,49$ \\
\hline
\end{tabular}

Patients who died within 30 days of their operation $(n=7)$ were excluded from the survival analyses.

(UICC) classification (1987) ${ }^{11}$ and the Dukes classification modified by Turnbull. ${ }^{12}$ All patients underwent operations. Twenty two were also treated with chemotherapy and 17 with radiotherapy. Follow up adhered to a standard protocol used in our clinic, and was generally undertaken by the same team of gastroenterologists. The pertinent data on the patients are summarised in table 1 .

\section{HISTOLOGICAL METHODS}

The tumour samples obtained at operation were immediately fixed in $10 \%$ buffered formalin ( $\mathrm{pH} 7.0)$ and embedded in paraffin. Several original sections from each of the primary tumours were re-examined by two observers unaware of the clinical data or the disease outcome, and the most representative tissue block was selected, cut at $5 \mu \mathrm{m}$ thickness, and stained with haematoxylin and eosin $(\mathrm{H} \& \mathrm{E})$ as well as for $\alpha$ catenin. Tumours were graded as well differentiated, moderately differentiated, or poorly differentiated (WHO grade). The histopathological data on patients are shown in table 1 .

\section{IMMUNOHISTOCHEMISTRY}

The $5 \mu \mathrm{m}$ thick paraffin sections were rehydrated and washed twice for 5 minutes with phosphate buffered saline (PBS). For $\alpha$ catenin analysis, the sections were heated in a microwave oven in $0.05 \mathrm{~mol} /$ litre Tris-HCL buffer ( $\mathrm{pH}=9.7$ ) for two 5 minute periods. Endogenous peroxidase activity was blocked with $5 \%$ $\mathrm{H}_{2} \mathrm{O}_{2}$ for 5 minutes, followed by two 5 minute washes with PBS. The tissue sections were incubated overnight at $4^{\circ} \mathrm{C}$ with a primary mouse monoclonal anti- $\alpha$-catenin antibody (Transduction Laboratories) at a working dilution of 1:100. After another washing step, bound antibody was localised using a biotinylated secondary antibody and avidin-biotinperoxidase detection kit (Vectastain ABC Elite kit, Vector Laboratories), in which diaminobenzidine tetrahydrochloride (DAB, Sigma) was the chromogen. Finally, the samples were slightly counterstained with haematoxylin, de- hydrated, cleared, and mounted with DePex $(\mathrm{BDH})$. In each staining batch, normal epithelium served as a positive control. In negative controls primary antibody was omitted.

EVALUATION OF STAINING

All slides were evaluated simultaneously with a dual head microscope (field diameter $490 \mu \mathrm{m}$ ) by two observers (KR and V-MK), both unaware of the clinical data. Disagreement in the assessment of staining was found in less than $10 \%$ of the slides examined, and consensus was reached on further review. The expression of $\alpha$ catenin in cancer cells was compared with that of normal epithelial cells in the same sample. Cancer cells which immunostained as strongly as normal colonic mucosa were defined as positive. $\alpha$ Catenin expression in the tumours was graded according to the proportion of positive cells. When more than $90 \%$ of cancer cells were positively stained, the tumours were considered as uniformly positive; when between $>10 \%$ and $90 \%$ were positively stained, the tumours were considered to be heterogeneous; when $0-10 \%$ of the cells were positively stained, the tumours were considered to be negative, as described previously. ${ }^{13-16}$. $\alpha$ Catenin localisation in tumour epithelium was evaluated as staining along the cell membranes (membranous), and as cytoplasmic involvement in addition to membranous staining. The intensity of the staining was scored as negative (0), weak (1), moderate (2), strong (3).

\section{ANALYSIS OF LYMPHOCYTE DENSITY}

The density of tumour infiltrating lymphocytes (TIL) was graded by two observers as absent, moderate, and dense, as described before. ${ }^{17}$ The TIL level was quantified from 10 microscopic fields $(40 \times)$, and the mean TIL value was calculated. TIL density was classified as: absent (grade 0), when $<10$ lymphocytes were obtained per high power field (HPF); weak (grade 1) when there were a few lymphocytes in the stroma and the inflammatory cell reaction around the tumour was mild $(10-50$ lymphocytes/HPF); dense (grade 3) when the tumour margins and stroma contained $>100$ lymphocytes/HPF; or moderate (grade 2) when the lymphocyte infiltrate in and around the tumour was intermediate between grades 1 and 3 (51-100 lymphocytes/HPF).

\section{STATISTICAL ANALYSIS}

We used the SPSS-X program package for statistical calculations. The differences between the means of continuous variables were tested by analysis of variance and frequency distributions by the $\chi^{2} .^{18}$ The univariate survival analysis was based on the life table method (log-rank analysis) with statistics by Gehan. Cancer related survival was measured from the date of surgery to the end of follow up or death. Recurrence-free survival was defined as the time elapsed between the primary treatment (date of surgery) and the date of recurrent tumour. Cases with metastases at diagnosis were not included when the recurrence-free survival was analysed. Survival analysis in- 

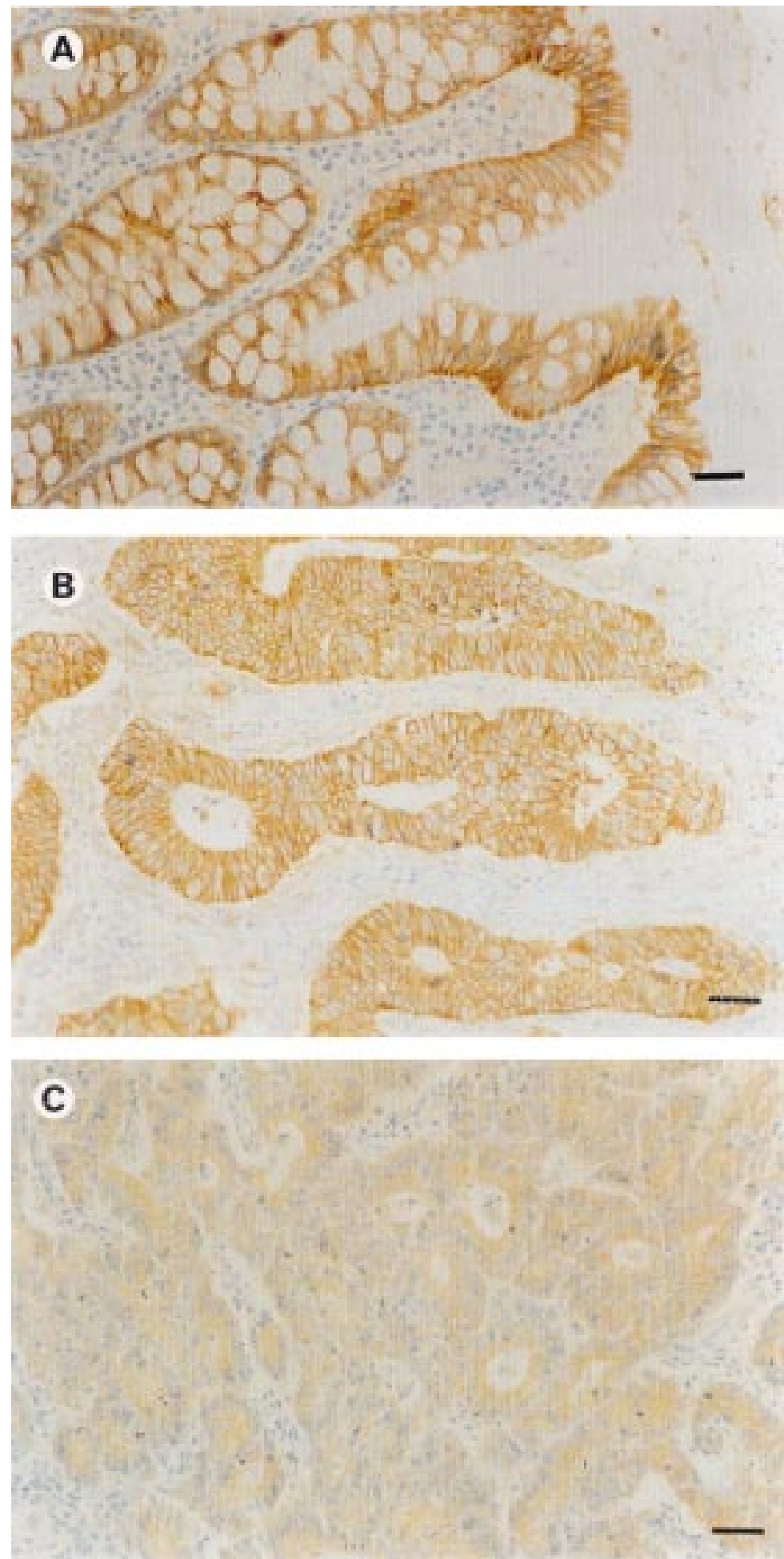

Figure 1 Immunohistochemical expression of a catenin in non-neoplastic human colonic mucosa and in colon carcinoma. (A) Sample of normal intestinal mucosa with intense a catenin positivity along cell membranes of epithelial cells. (B) Sample with $>90 \%$ of tumour cells intensely positive for a catenin. Note the staining pattern along cell membranes in tumour cells. (C) Sample with a reduced cytoplasmic signal for a catenin in tumour cells. Bar $=60 \mu \mathrm{m}$.

cluded (as an event) only the deaths from colorectal carcinoma. The causes of deaths were verified from the patients' files and death certificates. Deaths from postoperative complications within 30 days were excluded $(n=7)$. Multivariate survival analysis (Cox's regression analysis) was performed with the SPSS-X pro-
Table 2 Results of a catenin immunostaining

\begin{tabular}{llll}
\hline $\begin{array}{l}\text { l Catenin } \\
\text { intensity }\end{array}$ & $n(\%)$ & $\begin{array}{l}\text { Fraction of positive } \\
\text { cells (\%) }\end{array}$ & $n(\%)$ \\
\hline 0 & $8(4)$ & $0-10$ & $10(5)$ \\
1 & $71(38)$ & $>10-90$ & $94(50)$ \\
2 & $53(28)$ & $>90$ & $83(45)$ \\
3 & $55(30)$ & & 187 \\
Total & 187 & \\
$\begin{array}{l}\text { C Catenin localisation in } \\
\text { tumour epithelium }\end{array}$ & $n(\%)$ & \\
Negative & & \\
$\begin{array}{l}\text { Membranous staining } \\
\text { Membranous and } \\
\quad \text { cytoplasmic staining }\end{array}$ & $86(46)$ \\
Total & $93(50)$ \\
\hline
\end{tabular}

gram package in a stepwise manner ${ }^{19}$; the enter limit was $\mathrm{p}<0.05$ and the removal limit $p \geq 0.1$. Cox's proportional hazard model assess the contribution of the following baseline covariates: age, sex, tumour grade, tumour site (tumours involving rectum $(\mathrm{n}=90)$, or not $(n=97)$, Dukes classification, TNM stage, tumour infiltrating lymphocytes, and $\alpha$ catenin indices (intensity, proportion of positive cells, localisation). In the survival analyses low $\alpha$ catenin intensities ( 0 and 1$)$ were considered as one group and strong intensities (2 and 3 ) as another group. In addition, negative or heterogeneous tumours $(0-10 \%$ or $>10-90 \%)$ were considered as one group and positive tumours $(>90 \%)$ as another group. Similarly, tumours with membranous staining alone were considered as one group, and tumours with both membranous and cytoplasmic staining, along with negative tumours, as another group.

\section{Results}

EXPRESSION OF $\alpha$ CATENIN

The normal colonic mucosa in close vicinity to the tumours showed uniformly positive staining along cell membranes throughout the cellcell boundaries (fig 1A). Distribution of the $\alpha$ catenin expression intensities, the fractions of positive cells (\%), and the staining localisation in tumour epithelium is shown in table 2. Staining pattern along cell membranes (fig 1B) was observed in 86 tumours $(46 \%)$ and additional cytoplasmic accumulation (fig 1C) was present in 93 cases $(50 \%)$. The fraction of $\alpha$ catenin positive cells and staining intensity were strongly interrelated $\left(\chi^{2} 99.4, \mathrm{p}<0.001\right)$.

CORRELATION OF $\alpha$ CATENIN WITH OTHER PROGNOSTIC FACTORS

In high grade tumours, $\alpha$ catenin expression intensity was weaker and the fraction of positive cells lower than in low grade tumours (table 3). $\alpha$ Catenin localisation correlated with tumour grade. High grade tumours more often had both membranous and cytoplasmic staining $\left(\chi^{2} 13.0, p=0.01\right)$. There was also a relation between $\alpha$ catenin and TIL. $\alpha$ Catenin staining intensity was weak $\left(\chi^{2} 4.26, \mathrm{p}=0.03\right)$ and the fraction of positive cells low in tumours where lymphocytic infiltration was absent (0) or scanty $(1)\left(\chi^{2} 9.8, \mathrm{p}=0.002\right)$.

Table 4 shows that there was an association between the Dukes classification and $\alpha$ catenin expression. Intensity of $\alpha$ catenin expression in 
Table 3 Association between tumour grade, a catenin expression intensity, and fraction of positive cells

\begin{tabular}{|c|c|c|c|c|}
\hline & \multicolumn{3}{|c|}{ Tumour grade } & \multirow[b]{2}{*}{ Statistic } \\
\hline & $\begin{array}{l}1 \\
n(\%)\end{array}$ & $\begin{array}{l}2 \\
n(\%)\end{array}$ & $\begin{array}{l}3 \\
n(\%)\end{array}$ & \\
\hline \multicolumn{5}{|c|}{ a Catenin intensity in tumour epithelium } \\
\hline 0 & $1(2)$ & $3(3)$ & $4(15)$ & $\mathrm{p}=0.01$ \\
\hline 1 & $18(36)$ & $39(35)$ & $14(54)$ & $\chi^{2}=6.8$ \\
\hline 2 & $14(28)$ & $34(30)$ & $5(19)$ & \\
\hline 3 & $17(34)$ & $35(32)$ & $3(12)$ & \\
\hline \multicolumn{5}{|c|}{ Fraction of positive cells (\%) } \\
\hline $0-10$ & $1(1)$ & $4(4)$ & $5(19)$ & $\mathrm{p}<0.001$ \\
\hline$>10-90$ & $24(49)$ & $53(47)$ & $17(65)$ & $\chi^{2}=44.5$ \\
\hline$>90$ & $25(50)$ & $54(49)$ & $4(16)$ & \\
\hline
\end{tabular}

Table 4 Association between Dukes classification and a catenin expression intensity, fraction of positive cells, and localisation

\begin{tabular}{|c|c|c|c|c|c|c|}
\hline & \multicolumn{5}{|c|}{ Dukes classification } & \multirow[b]{2}{*}{ Statistic } \\
\hline & $\begin{array}{l}0 \\
n(\%)\end{array}$ & $\begin{array}{l}A \\
n(\%)\end{array}$ & $\begin{array}{l}B \\
n(\%)\end{array}$ & $\begin{array}{l}C \\
n(\%)\end{array}$ & $\begin{array}{l}D \\
n(\%)\end{array}$ & \\
\hline \multicolumn{7}{|c|}{ a Catenin intensity in tumour epithelium } \\
\hline 0 & $0(0)$ & $0(0)$ & $4(6)$ & $0(0)$ & $4(8)$ & $\mathrm{p}<0.001$ \\
\hline 1 & $1(50)$ & $4(13)$ & $20(27)$ & $22(69)$ & $24(49)$ & $\chi^{2}=21.9$ \\
\hline 2 & $0(0)$ & $10(32)$ & $24(33)$ & $6(19)$ & $13(27)$ & \\
\hline 3 & $1(50)$ & $17(55)$ & $25(34)$ & $4(12)$ & $8(16)$ & \\
\hline \multicolumn{7}{|c|}{ Fraction of positive cells } \\
\hline $0-10$ & $0(0)$ & $0(0)$ & $4(5)$ & $0(0)$ & $6(12)$ & $\mathrm{p}<0.001$ \\
\hline$>10-90$ & $0(0)$ & $5(16)$ & $27(37)$ & $27(84)$ & $35(71)$ & $\chi^{2}=44.5$ \\
\hline$>90$ & $2(100)$ & $26(84)$ & $42(58)$ & $5(16)$ & $8(17)$ & \\
\hline \multicolumn{7}{|l|}{ a Catenin localisation } \\
\hline Negative & $0(0)$ & $0(0)$ & $4(5)$ & $0(0)$ & $4(8)$ & $\mathrm{p}<0.001$ \\
\hline $\begin{array}{l}\text { Membranous } \\
\text { staining }\end{array}$ & $2(100)$ & $24(77)$ & $44(61)$ & $8(25)$ & $8(16)$ & $\chi^{2}=21.6$ \\
\hline $\begin{array}{l}\text { Membranous and } \\
\text { cytoplasmic } \\
\text { staining }\end{array}$ & $0(0)$ & $7(23)$ & $25(34)$ & $24(75)$ & $37(76)$ & \\
\hline
\end{tabular}

tumour epithelium and the proportion of positive carcinoma cells were both reduced in Dukes C and D tumours compared with A and B tumours. Dukes C and D tumours more often had additional cytoplasmic $\alpha$ catenin accumulation than Dukes A and B tumours.

SURVIVAL

Univariate analysis

Patients with negative or weak $\alpha$ catenin expression intensity ( 0 and 1$)$ or a low fraction of $\alpha$ catenin containing cells (0-90\%) had reduced survival compared with patients with a moderate or strong $\alpha$ catenin expression intensity (2 and 3 ) or a high fraction of $\alpha$ catenin containing cells (>90\%) (figs 2 and 3 ). There was also a correlation between localisation of $\alpha$ catenin staining and survival (fig 4). Patients with membranous $\alpha$ catenin positivity in tumour epithelium survived longer than patients with negative tumours or where the tumours expressed both membranous and cytoplasmic staining. In T1-3N0M0 tumours $(\mathrm{n}=92)$, patients with a moderate or strong $\alpha$ catenin expression intensity (2 and 3 ) in tumour epithelium survived for longer (75\% survived 10 years) than patients with weak or negative $\alpha$ catenin expression intensity ( 0 and 1) $(30 \%$ survived 10 years $)\left(\chi^{2} 8.3, p=0.004\right)$. There was no significant correlation between survival and the $\alpha$ catenin percentage fraction in this subgroup (data not shown).

Patients with a high or moderate $\alpha$ catenin expression intensity (2 and 3 ) and a high $\alpha$ cat-

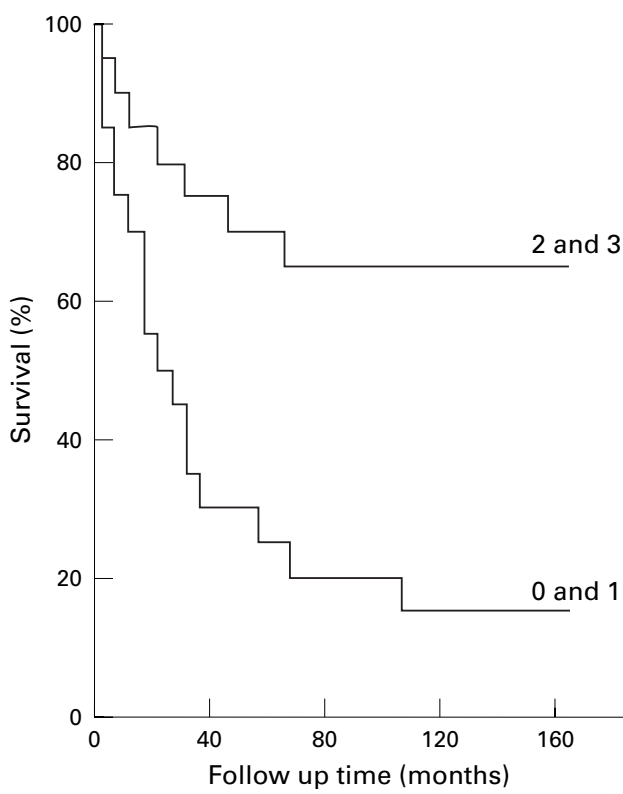

Figure 2 The survival of 173 patients categorised according to the a catenin expression intensity in tumour epithelium. The difference between the curves is highly significant $\left(\chi^{2} 29.3, p<0.001\right.$; curve 0 and $1=a$ catenin intensity 0 and $1, n=73$; curve 2 and $3=a$ catenin intensity 2 and $3, n=100$ ).

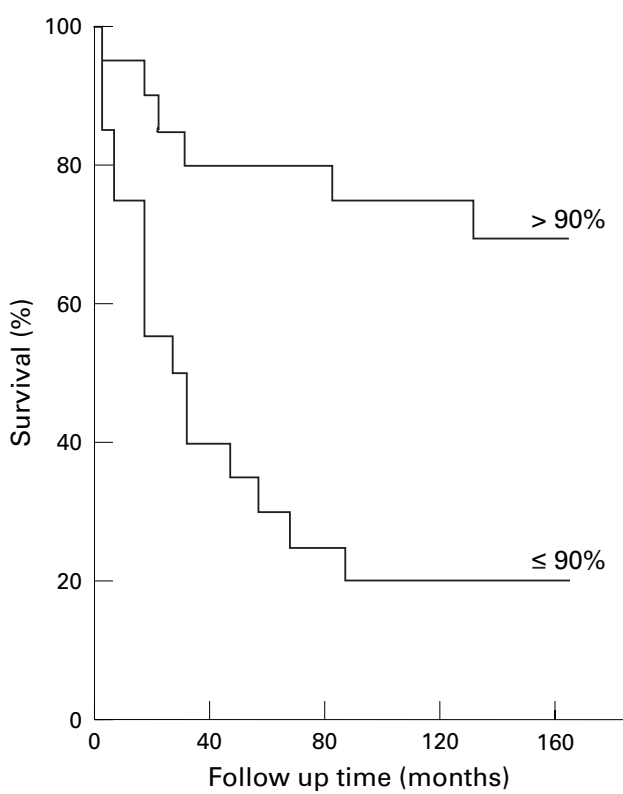

Figure 3 The survival of 173 patients categorised according to the a catenin percentage fraction in tumour epithelium. The difference between the curves is highly significant $\left(\chi^{2} 36.4, p<0.001\right.$. Curve $\leqslant 90 \%=0-90 \%$ a catenin containing cells, $n=96$; curve $>90 \%=>90 \%$ a catenin containing cells, $n=77$ ).

enin percentage fraction in tumour epithelium $(>90 \%)$ had longer recurrence-free survival than patients with a weak or negative $\alpha$ catenin expression intensity $(0$ and 1$)$ and a low $\alpha$ catenin percentage fraction (0-90\%) (figs 5 and $6)$. Membranous localisation of $\alpha$ catenin predicted a longer recurrence-free period $(70 \%$ survived recurrence-free for 10 years) compared with negative tumours or tumours with both membranous and cytoplasmic staining (25\% survived recurrence-free for 10 years) $\left(\chi^{2}\right.$ $27.2, \mathrm{p}<0.001)$. In the T1-3N0M0 subgroup, 


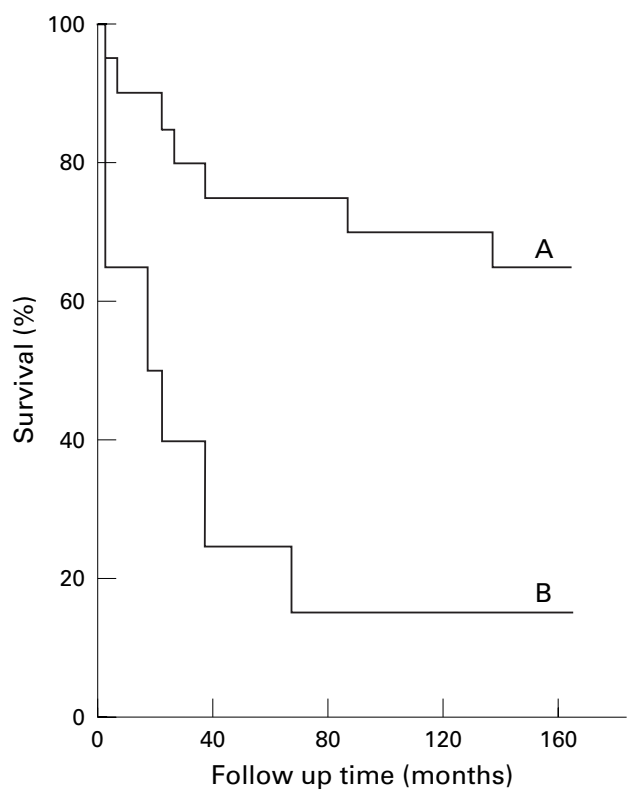

Figure 4 The survival of 173 patients categorised according to the a catenin localisation in tumour epithelium. The difference between the curves is highly significant $\left(\chi^{2} 13.1, p<0.001\right.$. Curve $A=a$ catenin expressed along cell membranes, $n=78$; curve $B=$ negative and additional cytoplasmic accumulation of a catenin, $n=95$ )

patients with strong or moderate $\alpha$ catenin expression intensity in tumour epithelium (2 and 3) survived for longer (70\% survived recurrence-free for 10 years) than patients with negative tumours or weak $\alpha$ catenin expression intensity ( 0 and 1$)$ (20\% survived recurrencefree for 10 years $)\left(\chi^{2}\right.$ 9.72, $\left.\mathrm{p}=0.002\right)$. Similarly, patients with $>90 \%$ of $\alpha$ catenin positive cells survived for longer $(70 \%$ survived recurrence-free for 10 years) than patients with $0-90 \%$ of $\alpha$ catenin positive cells $(25 \%$ survived recurrence-free for 10 years $)\left(\chi^{2} 7.80\right.$, $\mathrm{p}=0.005)$. Seventy per cent of patients with a membranous $\alpha$ catenin staining pattern survived recurrence-free for 10 years, compared with $25 \%$ of those with $\alpha$ catenin negative tumours or with additional cytoplasmic staining $\left(\chi^{2} 12.4, \mathrm{p}<0.001\right)$.

Chemotherapy or radiotherapy combined with primary surgical treatment had no effect on survival. Neither chemotherapy nor radiotherapy for treatment of recurrent disease had any prognostic value, since the treatments were given at a very late stage of the disease as a palliative measure. In addition, the type of surgery had no effect on survival or recurrence-free survival, either in the group as a whole $(n=187)$ or in those with Dukes B stage tumours.

\section{Multivariate analysis}

The results of multivariate survival analyses are shown in table 5 . In the group as a whole and in T1-4N0-3M0 and T1-3N0M0 patients, $\alpha$ catenin intensity in tumour epithelium significantly predicted survival. In T1-4N0-3M0 and T1-3N0M0 patients $\alpha$ catenin localisation was a significant predictor of recurrence-free survival. Patients with a membranous staining pattern in their tumours survived for longer.

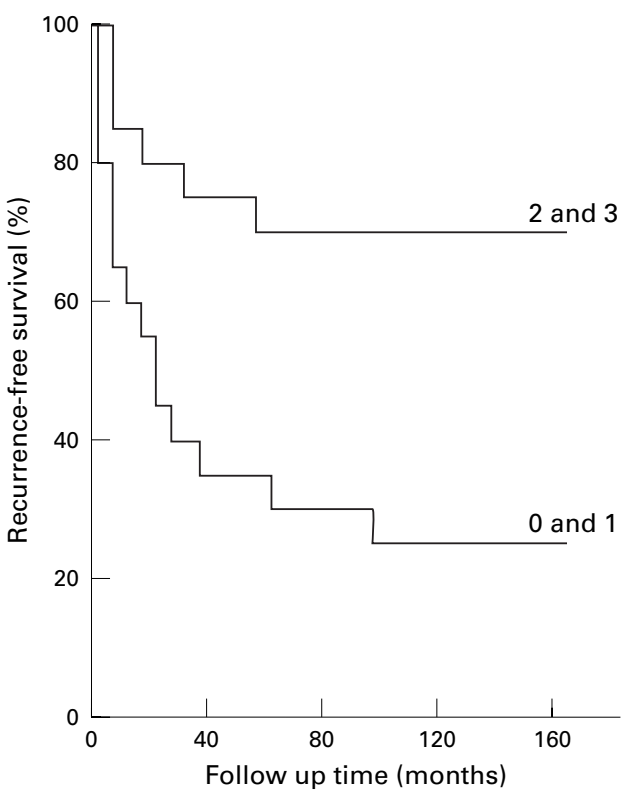

Figure 5 The recurrence-free survival of 128 patients categorised according to the a catenin expression intensity in tumour epithelium. The difference between the curves is highly significant $\left(\chi^{2} 25.5, p<0.001\right.$. Curve 0 and $1=$ a catenin intensity 0 and $1, n=47 ;$ curve 2 and $3=$ a catenin intensity 2 and $3, n=81$ ).

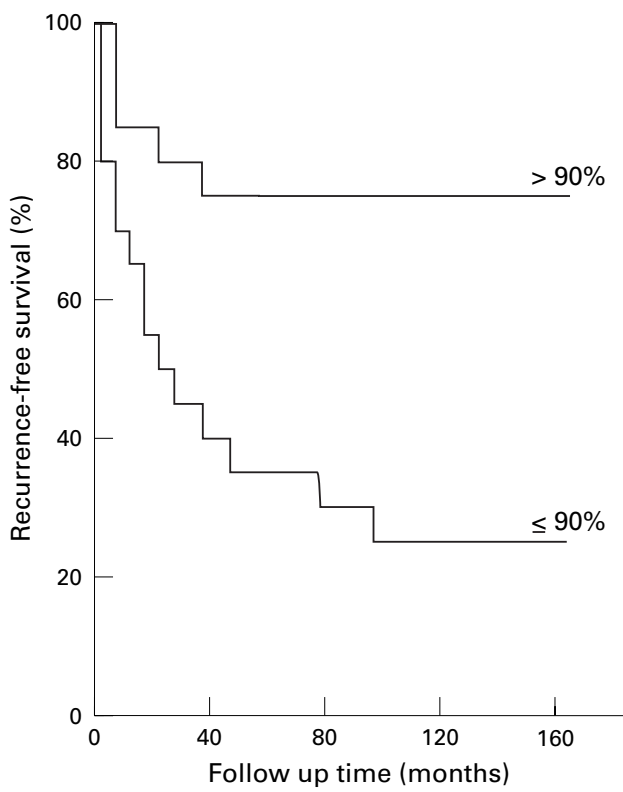

Figure 6 The recurrence-free survival of 128 patients categorised to the a catenin percentage fraction in tumour epithelium. The difference between the curves is highly significant $\left(\chi^{2} 20.4, p<0.001\right.$. Curve $\leqslant 90 \%=0-90 \%$ a catenin containing cells, $n=57 ;$ curve $>90 \%=>90 \%$ a catenin containing cells, $n=71$ ).

Accordingly, in Dukes B patients ( $n=68), \alpha$ catenin intensity was an independent prognostic factor for survival $(\mathrm{p}=0.001$, relative risk (RR) 0.28 (95\% confidence interval (CI) 0.13 to 0.60 ). In addition, significant prognostic factors for recurrence-free survival in Dukes B patients $(n=68)$ were $\alpha$ catenin localisation and gender (men survived for longer) ( $\mathrm{p}=0.001, \mathrm{RR} 0.31$ (95\% CI 0.15 to 0.63$)$; and $\mathrm{p}=0.03, \mathrm{RR}=2.15(95 \%$ CI 1.06 to $4.34)$, respectively. In all multivariate survival analyses, the log-minus-log (LML) survival 
Table 5 Independent predictors of survival and recurrence-free survival in a Cox analysis

\begin{tabular}{|c|c|c|c|}
\hline Category & $\beta(S E)$ & $p$ Value & Hazard rate $(95 \% \mathrm{CI})$ \\
\hline \multicolumn{4}{|l|}{$\begin{array}{l}\text { Survival } \\
\text { All cases }(n=173)\end{array}$} \\
\hline Dukes & $0.833(0.117)$ & $<0.001$ & $2.30(1.83$ to 2.89$)$ \\
\hline$\alpha$ Catenin intensity & $-1.135(0.235)$ & $<0.001$ & $0.32(0.20$ to 0.51$)$ \\
\hline Sex (male) & $0.592(0.222)$ & 0.008 & $1.82(1.17$ to 2.79$)$ \\
\hline \multicolumn{4}{|l|}{$T 1-4 N 0-3 M 0(n=128)$} \\
\hline $\mathrm{N}$ category & $0.753(0.222)$ & 0.001 & $2.12(1.37$ to 3.28$)$ \\
\hline$\alpha$ Catenin intensity & $-1.381(0.317)$ & $<0.001$ & $0.25(0.14$ to 0.47$)$ \\
\hline \multicolumn{4}{|l|}{ T1-3NOMO $(n=92)$} \\
\hline$\alpha$ Catenin intensity & $-1.562(0.390)$ & $<0.001$ & $0.22(0.10$ to 0.45$)$ \\
\hline \multicolumn{4}{|c|}{ Recurrence-free survival } \\
\hline$\alpha$ Catenin localisation & $-1.092(0.295)$ & 0.002 & $0.34(0.19$ to 0.60$)$ \\
\hline $\mathrm{N}$ category & $0.642(0.218)$ & 0.003 & $1.90(1.24$ to 2.91$)$ \\
\hline $\mathrm{T}$ category & $0.518(0.241)$ & 0.03 & $1.68(1.05$ to 2.69$)$ \\
\hline $\begin{array}{l}\text { T1-3NOMO }(n=92) \\
\alpha \text { Catenin localisation }\end{array}$ & $-1.489(0.347)$ & $<0.001$ & $0.23(0.11$ to 0.45$)$ \\
\hline
\end{tabular}

$\beta$, coefficient of regression model; CI, confidence interval; SE, standard error of $\beta$.

plot showed a constant increase in the cumulative hazard rate during the follow up period.

\section{Discussion}

Cell-cell adhesion in epithelial cells is mediated by the cell surface protein E-cadherin in association with $\alpha$ catenin and $\beta$ catenin, which link E-cadherin to the cytoskeleton. ${ }^{4}$ Shimazui et al have reported that the reduced expression of catenins and E-cadherin correlates with poor prognosis, and all three molecules have a similar prognostic value in bladder tumours. ${ }^{20}$ Similarly, reduced expression of these three protein molecules is also correlated with less favourable clinicopathological features in oesophageal cancer, where E-cadherin and $\beta$ catenin are considered to be independent of staging and are thought to be better prognostic indicators than $\alpha$ catenin. ${ }^{15}$ In contrast, recent studies on oesophageal, renal, and breast cancers have suggested that the immunohistochemical assessment of $\alpha$ catenin might be better than that of the other catenins and E-cadherin for assessing prognosis. ${ }^{521}$ This may be explained by their role in the cadherincatenin complex. Both $\beta$ and $\gamma$ catenin can bind directly to cadherin, whereas $\alpha$ catenin plays an essential role in the linkage of the $\beta / \gamma$ catenin complex to the cytoskeleton. Therefore a functional complex can be present only with normal $\alpha$ catenin expression, whereas aberrant expression of either $\beta$ or $\gamma$ catenin does not necessarily lead to a non-functional complex. ${ }^{8}$ Consequently, the prognostic role of $\alpha$ catenin expression in human tumours is still unclear. With this in mind we investigated $\alpha$ catenin expression in colorectal cancer and its relation to patient survival.

The downregulation of $\alpha$ catenin was observed both in Dukes C and D tumours, and in high grade tumours. This finding is in line with the observation that reduced $\alpha$ catenin expression has been shown to be significantly related to poor differentiation, depth of invasion, infiltrative growth, and lymph node metastasis in carcinomas of the human gastrointestinal tract. ${ }^{1521}$ Similarly, reduced E-cadherin expression is linked with tumour dedifferentation and advanced stage in colorec- tal cancer. ${ }^{16}$ Breen et al have shown that the restoration of a functional E-cadherin/catenin complex significantly diminishes the ability of a poorly differentiated colon carcinoma cell line to migrate on two matrix proteins that are thought to play a major role in tumour invasion-laminin and collagen I. ${ }^{4}$ These data support the view that cell-cell adhesion is a major determinant of carcinoma cell behaviour. ${ }^{4}$ In addition, our observation that Dukes C and B tumours had both low $\alpha$ catenin signals and an absent or weak TIL reaction emphasises the importance of tumour-host interactions in human neoplasms.

Cytoplasmic localisation of $\alpha$ catenin was detected in Dukes C and D tumours, and in high grade tumours, whereas in normal colorectal epithelium only membranous staining was observed. Van der Wurff et al observed weak cytoplasmic staining of both $\alpha$ and $\beta$ catenin in colorectal adenomas and in carcinomas, and all lymph node and liver metastases displayed cytoplasmic staining of variable intensity. ${ }^{22}$ Some oesophageal and gastric cancers have been shown to have reduced $\alpha$ and $\beta$ catenin expression levels and reduced cytoplasmic staining. ${ }^{153}$ Functional and structural aberrations in cancer cells as well as abnormalities in post-transitional processing might be involved in the cytoplasmic targeting of $\alpha$ catenin. Moreover, $\alpha$ and $\beta$ catenin, as well as E-cadherin, are known to be associated with the APC tumour suppressor gene; this association is stronger and more specific than similar associations in any other type of sporadic epithelial tumour. ${ }^{24}$ Most of the mutations in APC result in truncated APC protein, which can complex with but not degrade $\beta$ catenin. The net result of APC mutation is an increase in cytoplasmic $\beta$ catenin, which may then trigger a cascade of events resulting in the initiation of adenomas. ${ }^{25}$ However, the exact mechanisms behind the cytoplasmic expression of catenins remain to be clarified in future studies.

We also included established prognostic factors in our study, to test the relevance of the $\alpha$ catenin expression. Strong $\alpha$ catenin expression intensity, a high fraction of positive cells, and membranous localisation of $\alpha$ catenin positivity in tumour epithelium predicted longer absolute and recurrence-free survival. In the multivariate analysis, where all important traditional prognostic factors were taken into consideration, $\alpha$ catenin expression intensity in tumour epithelium was still an independent predictor of survival. In addition, $\alpha$ catenin localisation independently predicted recurrence-free survival. However, it should be noted that staining patterns varied within the tumour, probably because of variations in differentiation in different parts of the tumour. Also the fixation methods used might have interfered with the evaluation of adhesion molecules so far as the clinicopathological findings and patient outcome are concerned. To overcome these problems, immunostaining was evaluated using the adjacent normal colonic mucosa as an internal positive control. Our method of evaluation has 
been used successfully before, ${ }^{13-16}$ and it seems to be reliable for scoring purposes. For the survival analyses, case groups were merged (figs $2-6)$ to relate $\alpha$ catenin expression to survival; this showed that in colorectal cancer patients who had an apparently radical resection of their primary tumour, $\alpha$ catenin expression seemed to act as an independent prognostic variable. Thus the results of our study are in line with the findings in renal cell carcinoma, where aberrant $\alpha$ catenin expression was correlated with survival in T1-3N0M0 patients and was also a significant prognostic indicator in a Cox analysis. ${ }^{8}$ Furthermore, radically treated prostate cancer patients with aberrant $\alpha$ catenin expression seem to have more rapid disease progression than patients with normal $\alpha$ catenin expression. ${ }^{9}$ Finally, in oesophageal cancer, survival of patients with reduced $\alpha$ catenin expression was significantly reduced compared with those with normal expression. ${ }^{26}$

In conclusion, reduced expression of $\alpha$ catenin in colorectal cancer is an unfavourable sign. $\alpha$ Catenin expression and localisation are also significant in predicting survival, especially in T1-3N0M0 and Dukes B patients. Because of its independent prognostic value, $\alpha$ catenin could be used to identify patients with greater risk of disease progression, who might benefit from early adjuvant therapy.

This study was financially supported by North Savo Cancer Fund and the EVO funds of Kuopio University Hospital. We thank Mrs Aija Korkalainen and Ms Eeva Oittinen for their skilful immunohistochemical and secretarial assistance.

1 Jass JR, Love SB, Northover JM. A new prognostic classification of rectal cancer. Lancet 1987;i:303-6.

2 Potter JD, Slattery ML, Bostick RM, et al. Colon cancer: a review of the epidemiology. Epidemiol Rev 1993;15:499545 .

3 Ilyas $M$, Novelli $M$, Wilkinson $K$, et al. Tumour recurrence is associated with Jass grouping but not with differences in B colorectal cancers. $\mathcal{F}$ Clin Pathol 1997;50:218-22.

4 Breen E, Steele G, Mercurio AM. Role of the E-cadherin alpha-catenin complex in modulating cell-cell and cell-

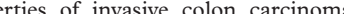
cells. Ann Surg Oncol 1995;2:378-85.

5 Kadowaki T, Shiozaki H, Inoue M, et al. E-cadherin and $\alpha$-catenin expression in human esophageal cancer. Cancer Res 1994;54:291-6.
6 Jiang WG. E-cadherin and its associated protein catenins, Jiang WG. E-cadherin and its associated protein catenins, 7 Chen WC, Obrink C. Cell-cell contacts mediated by E-cadherin (uvomorulin) restrict invasive behavior of L-cells. F Cell Biol 1991;114:319-27.

8 Shimazui T, Bringuier PP, Van Berkel H, et al. Decreased expression of $\alpha$-catenin is associated with poor prognosis of patients with localized renal cell carcinoma. Int $\mathcal{F}$ Cancer (Pred Oncol) 1997;74:523-8.

9 Umbas R, Isaacs WB, Bringuier PP, et al. Relation between aberrant $\alpha$-catenin expression and loss of E-cadherin function in prostate cancer. Int 7 Cancer (Pred Oncol) 1997;74: 374-7.

10 Hashizume R, Koizumi H, Ihara A, et al. Expression of $\beta$-catenin in normal breast tissue and breast carcinoma: a comparative study with epithelial cadherin and $\alpha$-catenin. Comparative study with epithelial

11 UICC. In: Hermannek P, Sobin LH, eds. TNM classification of malignant tumours, 4 th ed. Berlin: Springer, 1987.

12 Turnbull RB, Kyle K, Watson FB, et al. Cancer of the colon: the influence of the no-touch isolation technique on survival rates. Ann Surg 1967;166:400-27.

13 Oka H, Shiozaki H, Kobayashi K, et al. Immunohistochemical evaluation of E-cadherin adhesion molecule expression in human gastric cancer. Virchows Arch 1992;421:149-56.

14 Umbas R, Schalken JA, Aalders TW, et al. Expression of cellular adhesion molecule E-cadherin is reduced or absent in lular adhesion molecule E-cadherin is reduced or absent
high-grade prostate cancer. Cancer Res 1992;52:5104-9.

15 Krishnadath KK, Tilanus HW, Van Blankenstein M, et al. Reduced expression of the cadherin-catenin complex in oesophageal adenocarcinoma correlates with poor prognosis. F Pathol 1997;182:331-8.

16 Valizadeh A, Karayiannakas I, Kmiot W, et al. Expression of E-cadherin-associated molecules $(\alpha-, \beta-$, and $\gamma$-catenins and p120) in colorectal polyps. Am f Pathol 1997;150: 1977-83.

17 Ropponen KM, Eskelinen MJ, Lipponen PK, et al. Prognostic value of tumour infiltrating lymphocytes (TILs) in colorectal cancer. $\mathcal{F}$ Pathol 1997;182:318-24.

18 Mantel N, Haeszel W. Statistical aspects of the analysis of data from retrospective studies of disease. 7 Natl Cancer Inst data from retrospecti

19 Cox DR. Regression models and life tables with discussion. F R Stat Soc B 1972;34:187-92.

20 Shimazui T, Schalken JA, Giroldi LA, et al. Prognostic value of cadherin-associated molecules $(\alpha-, \beta-$, and $\gamma$-catenins and $\left.120^{\mathrm{cas}}\right)$ in bladder tumors. Cancer Res 1996;56:41548.

21 Rimm DL, Sinard JH, Morrow JS. Reduced $\alpha$-catenin and E-cadherin expression in breast cancer. Lab Invest 1995;72: 506-12.

22 Van Der Wurff AAM, Vermeulen SJT, Van Der Linden EPM, et al. Patterns of $\alpha$ - and $\beta$-catenin and E-cadherin expression in colorectal adenomas and carcinomas. F Pathol 1997;182:325-330.

23 Matsui S, Shiozaki H, Inoue M, et al. Immunohistochemical evaluation of alpha-catenin expression in human gastric cancer. Virchows Arch 1994;424:375-81

24 Midgley CA, White S, Howitt R, et al. APC expression in normal human tissues. F Pathol 1997;181:426-33.

25 Ilyas M, Tomlinson IP. The interactions of APC, E-cadherin and B-catenin in tumour development and progression. $\mathcal{F}$ Pathol 1997;182:128-37.

26 Nakanishi Y, Ochiai A, Akimoto S. Expression of E-cadherin, $\alpha$-catenin, $\beta$-catenin and plakoglobin in esophageal carcinomas and its prognostic significance. Lab Invest 1997;54:158-65. 